\title{
Editorial
}

\section{Experimental Game Theory and Its Application in Sociology and Political Science}

\author{
Arthur Schram, ${ }^{1,2}$ Vincent Buskens, ${ }^{3}$ Klarita Gërxhani, ${ }^{4}$ and Jens Großer ${ }^{5}$ \\ ${ }^{1}$ CREED, University of Amsterdam, Plantage Muidergracht 14, 1018 TV Amsterdam, Netherlands \\ ${ }^{2}$ Robert Schuman Centre for Advanced Studies, European University Institute, Fiesole, Italy \\ ${ }^{3}$ Department of Sociology/ICS, Utrecht University, Padualaan 14, 3584 CH Utrecht, Netherlands \\ ${ }^{4}$ Department of Political and Social Sciences, European University Institute, Via Roccettini 9, San Domenico di Fiesole, \\ 50014 Fiesole, Italy \\ ${ }^{5}$ Department of Political Science, Florida State University, Bellamy Hall 531, Tallahassee, FL 32306-2230, USA
}

Correspondence should be addressed to Arthur Schram; schram@uva.nl

Received 13 August 2015; Accepted 16 August 2015

Copyright (C) 2015 Arthur Schram et al. This is an open access article distributed under the Creative Commons Attribution License, which permits unrestricted use, distribution, and reproduction in any medium, provided the original work is properly cited.

Game theory, laboratory experiments, and field experiments are common and powerful tools in many social sciences [1]. However, applications in Sociology and Political Science remain scarce and scattered [2]. Yet, the combination of game theory with controlled experiments provides a powerful tool to better understand social and political processes, for example, [3-5]. The mathematical structure offered by game theory and the control offered by an experimental environment allow the researcher to isolate sociological and/or political phenomena to study their development and their effects. The relationship between game theory and experiments is twofold. On the one hand, game theory provides solid ground on which to design an experiment and a formal benchmark that serves as a measuring rod for a structured analysis of observed behavior. On the other hand, experiments can be used to test equilibrium predictions and to pinpoint shortcomings of theory as well as point to directions in which the theory can be adapted.

The aim of the special issue is to encourage original research that seeks to study sociological or political phenomena using laboratory experiments that are based on game theoretical benchmarks and that seek mathematical modeling of game theoretical arguments to inspire experiments in the fields of Sociology and Political Science, and vice versa.

In a research article of the special issue, G. Bravo et al. experimentally study whether intermediaries can positively influence cooperation between a trustor and a trustee in an investment or trust game. Another article by L. A. Palacio et al. develops a game theoretical foundation for experimental investigations of the strategic role in games with nonbinding communication. In another article, L. Corazzini and M. Tyszler employ quantal response equilibrium (QRE) to find out the extent of confusion and efficiency motives of laboratory participants in their decisions to contribute to public good. The article by S. A. Tulman utilizes QRE (i.e., noisy decision-making) and altruism-motivated players to investigate the "paradox of voter turnout" in a participation game experiment. Finally, in another article, B. Kittel et al. present a laboratory study in which they examine the role of the middle class on income distribution within the framework of a contest game.

We hope that the selection of articles in this special issue will help to inspire scholars in Sociology and Political Science to add mathematics to their tool box and adopt game theory and experimentation in their research methodology. 


\section{Acknowledgment}

We sincerely thank all the authors and reviewers who contributed greatly to the success of the special issue.

\section{Arthur Schram \\ Vincent Buskens \\ Klarita Gërxhani \\ Jens Großer}

\section{References}

[1] A. Falk and J. J. Heckman, "Lab experiments are a major source of knowledge in the social sciences," Science, vol. 326, no. 5952, pp. 535-538, 2009.

[2] M. Jackson and D. R. Cox, "The principles of experimental design and their application in sociology," Annual Review of Sociology, vol. 39, pp. 27-49, 2013.

[3] R. Corten and V. Buskens, "Co-evolution of conventions and networks: an experimental study," Social Networks, vol. 32, no. 1, pp. 4-15, 2010.

[4] K. Gërxhani, J. Brandts, and A. Schram, "The emergence of employer information networks in an experimental labor market," Social Networks, vol. 35, no. 4, pp. 541-560, 2013.

[5] J. Großer and A. Schram, "Public opinion polls, voter turnout, and welfare: an experimental study," American Journal of Political Science, vol. 54, no. 3, pp. 700-717, 2010. 


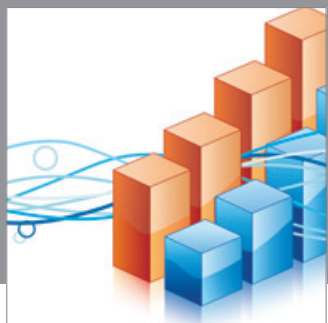

Advances in

Operations Research

mansans

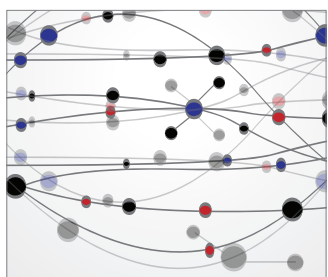

The Scientific World Journal
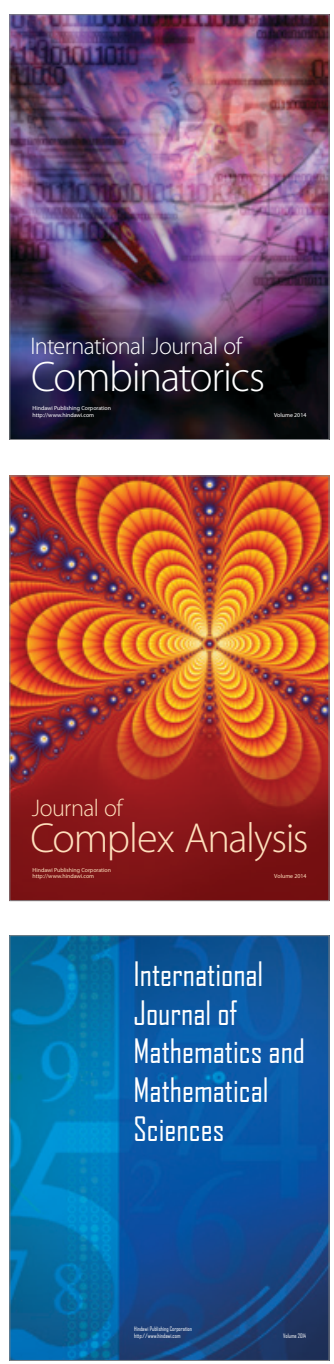
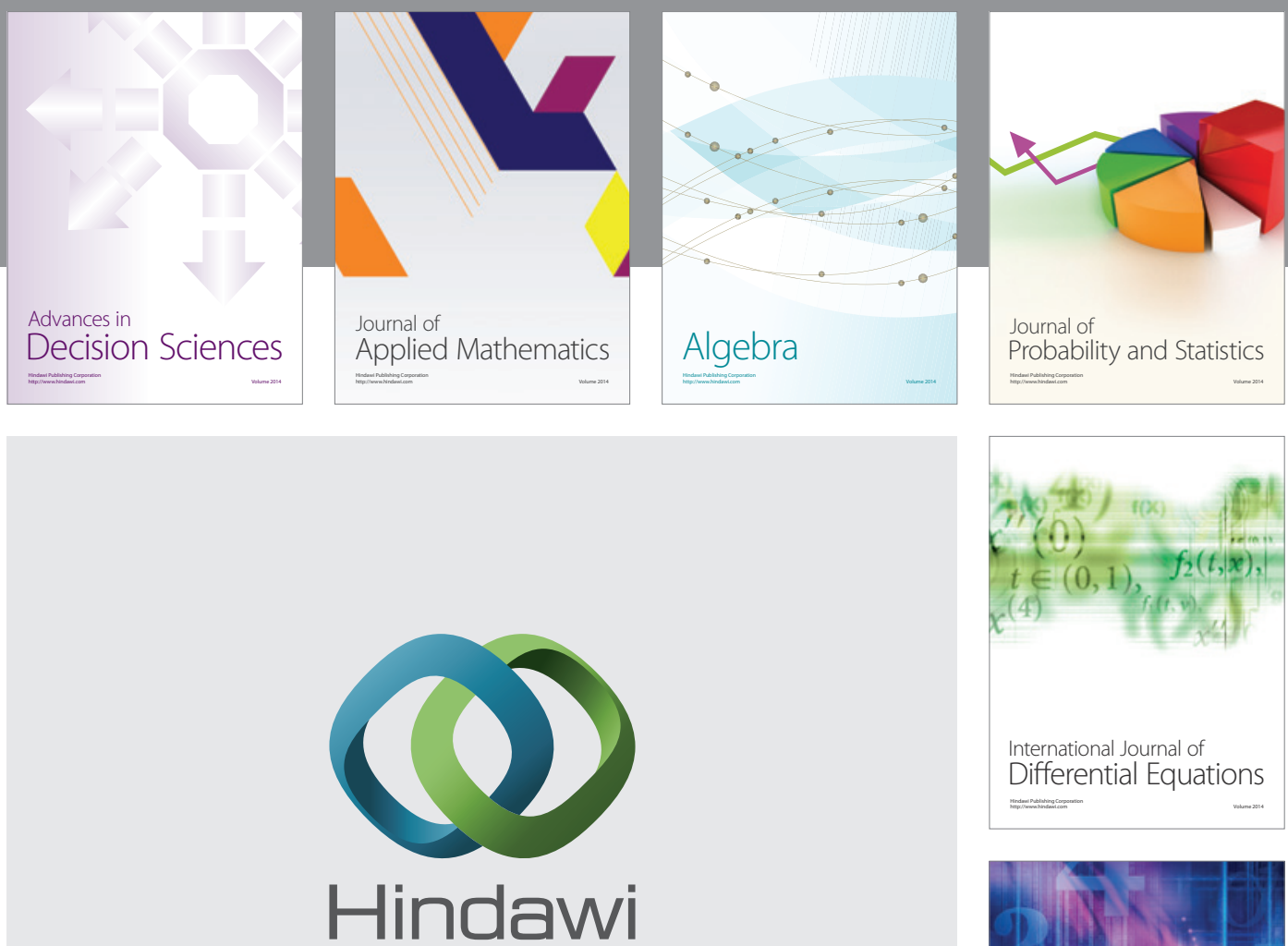

Submit your manuscripts at http://www.hindawi.com
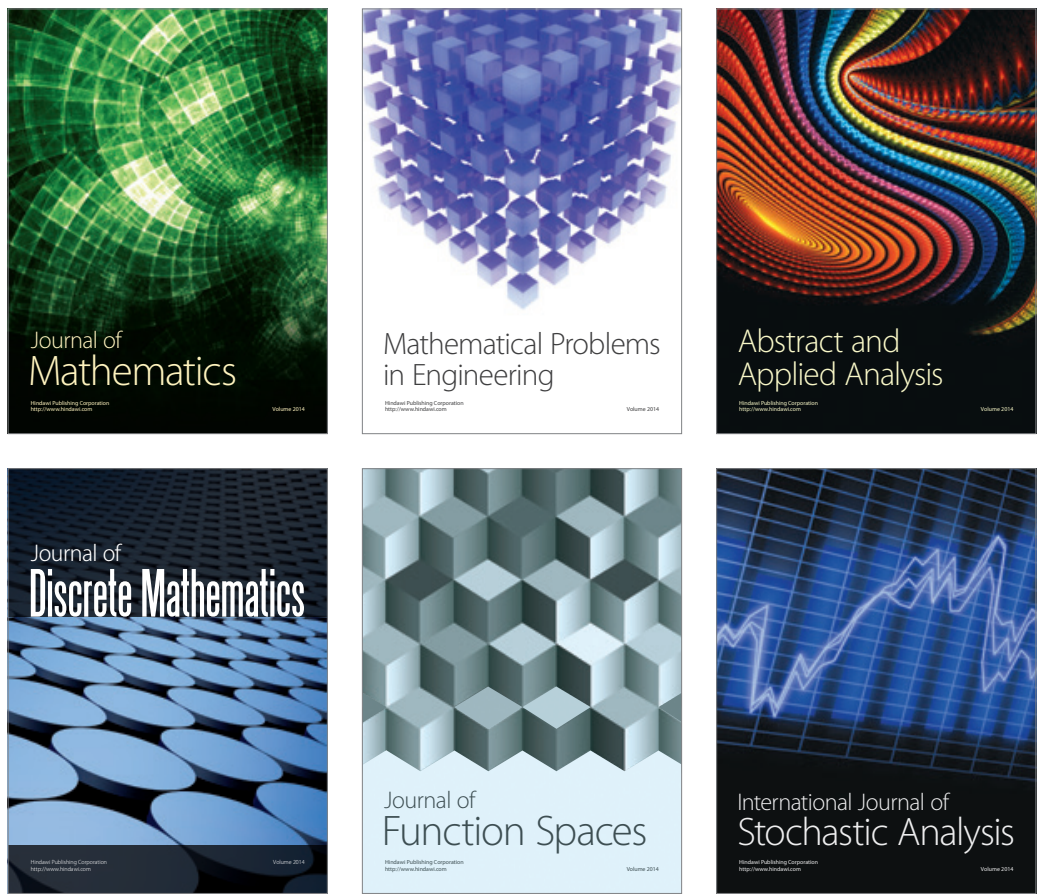

Journal of

Function Spaces

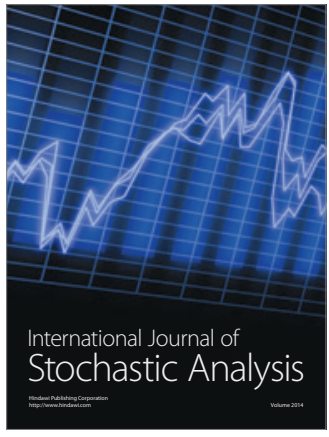

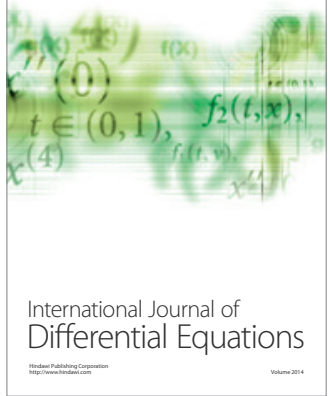
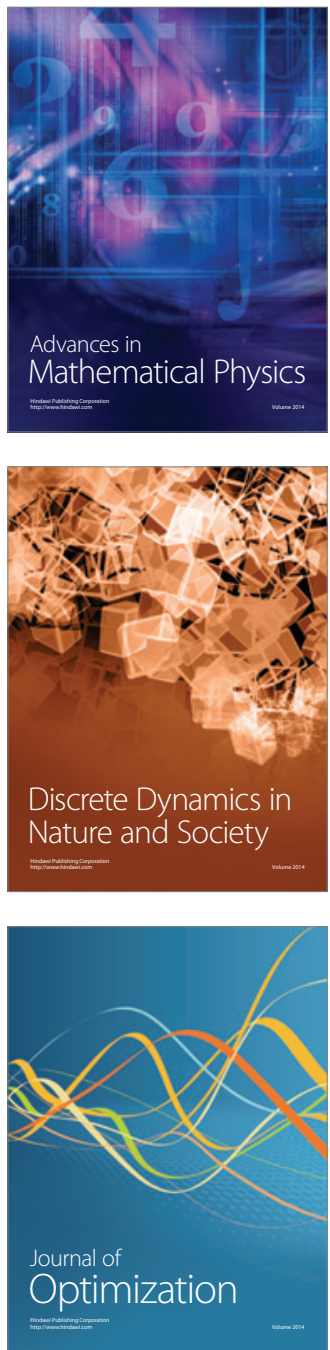